\title{
A Cross Sectional Study on the Pattern and Association of Hyperlipidaemia in Patients with Cholelithiasis
}

\author{
Rama Saha ${ }^{1}$, Sudipta Bhattacharyya르, Suman Ghosh ${ }^{3}$ \\ ${ }^{1}$ Senior Resident, Department of Pathology, ESI-PGIMSR, Manicktala, Kolkata, West Bengal, India. ${ }^{2}$ Associate \\ Professor, Department of Pathology, Nil Ratan Sircar Medical College and Hospital, Kolkata, West Bengal, India. \\ ${ }^{3}$ Assistant Professor, Department of Pathology, Nil Ratan Sircar Medical College and Hospital, Kolkata, West Bengal, \\ India.
}

\section{ABSTRACT}

\section{BACKGROUND}

Gall stones constitute a major world health problem afflicting $10-20 \%$ of adult population in developed countries. There are two main types of gall stones. In the West, about $90 \%$ are cholesterol stones, containing more than $50 \%$ of crystalline cholesterol monohydrate. The rest are pigment stones. Cholesterol gall stones are more prevalent in the United States and Western Europe and uncommon in developing countries. Advancing age, female gender, obesity, metabolic syndrome and hyperlipidaemia are the risk factors for formation of cholesterol stones. We wanted to evaluate the association between serum lipid profile and gall stones, compare the lipid profiles of cholelithiasis patients with a control group and study the histopathological changes in gallbladder in the study population.

\section{METHODS}

This is a cross sectional study done to evaluate the distribution of different types of gallstones in patients attending Burdwan Medical College \& Hospital. Study sample consisted of 54 calculous cholecystitis cases undergoing cholecystectomy during the study period in Department of General Surgery, Burdwan Medical College. Study period commenced from February-2014 and continuing till January-2015. 51 age and sex matched controls were included in the study. Using autoanalyser, the following five parameters were measured- total cholesterol, triglycerides, highdensity cholesterol, low density cholesterol, very low-density cholesterol. All the specimens for histopathological examination were collected and sent to the Department of Pathology, Burdwan Medical College in formalin-filled containers.

\section{RESULTS}

Gallstone disease is common in the age group of 31-40 years. There is a female preponderance. Cholesterol stones constitute the majority among the two main types of stones. There was a statistically significant increase in the serum total cholesterol and serum LDL levels, but no significant change in the serum triglycerides, HDL and VLDL levels in cholelithiasis patients compared to the control group.

\section{CONCLUSIONS}

There was a significant association of cholelithiasis with high serum cholesterol ( $>200 \mathrm{mg} / \mathrm{dl}$ ) and LDL ( $>130 \mathrm{mg} / \mathrm{dl}$ ) levels and, but no such association was found with high serum triglycerides ( $\geq 150 \mathrm{mg} / \mathrm{dl}$ ) or low serum HDL ( $<40 \mathrm{mg} / \mathrm{dl})$ levels.

\section{KEY WORDS}

Hyperlipidaemia, Cholecystitis, Gall Bladder Stone, Cholelithiasis
Corresponding Author: Dr. Sudipta Bhattacharyya, P-99, LIC Township, Madhyamgram, Kolkata-700129 West Bengal, India.

E-mail:doctordadas@yahoo.com

DOI: $10.14260 / \mathrm{jemds} / 2019 / 609$

Financial or Other Competing Interests: None.

How to Cite This Article:

Saha R, Bhattacharyya S, Ghosh S. A cross sectional study on the pattern and association of hyperlipidaemia in patients with cholelithiasis. J. Evolution Med. Dent. Sci. 2019;8(36):2807-2812, DOI: $10.14260 /$ jemds/2019/609

Submission 09-07-2019,

Peer Review 24-08-2019,

Acceptance 30-08-2019,

Published 09-09-2019. 


\section{BACKGROUND}

Gall stones are a major health problem afflicting $10-20 \%$ of adult population in developed countries. There has been intense research regarding their pathogenesis providing new insights. There are two main types of gall stones. In the West, about $90 \%$ are cholesterol stones, containing more than $50 \%$ of crystalline cholesterol monohydrate. The rest are pigment stones composed predominantly of bilirubin calcium salts. Cholesterol gall stones are more prevalent in the United States and Western Europe and uncommon in developing countries. Advancing age, female gender, obesity, metabolic syndrome and hyperlipidaemia are the risk factors for formation of cholesterol stones.

Gallstones are formed because of abnormal bile composition. Cholesterol is essentially water insoluble and requires aqueous dispersion into either micelles or vesicles, both of which require the presence of a second lipid to solubilise the cholesterol. Cholesterol and phospholipids are secreted into bile as uni-lamellar bilayered vesicles, which are converted into mixed micelles consisting of bile acids, phospholipids, and cholesterol by the action of bile acids. If there is an excess of cholesterol in relation to phospholipids and bile acids, unstable, cholesterol-rich vesicles remain, which aggregate to form large multilamellar vesicle. Cholesterol gallstone disease occurs because of several defects, which include(1) bile super-saturation with cholesterol,(2) nucleation of cholesterol monohydrate with subsequent crystal retention and stone growth, and(3) abnormal gallbladder motor function with delayed emptying and stasis from which cholesterol crystals precipitate.

Gall stones are formed because of abnormal bile composition. They are divided into two major types: Cholesterol stones - more than $80 \%$ of the total. They usually contain $>50 \%$ cholesterol monohydrate plus an admixture of calcium salts, bile pigments, and proteins. Pigment stones less than $20 \%$. They are composed primarily of calcium bilirubinate; they contain $<20 \%$ cholesterol and are classified into "black" and "brown" types, the latter forming secondary to chronic biliary infection. There is a female preponderance. Cholesterol stones constitute the majority among the main two types of stones.

The aim of the present study was to find out the association between serum lipid profile and gall stones and to compare the lipid profiles of cholelithiasis patients with a control group. Specific objectives of this study were to study the patterns of different types of stones in the surgically removed gallbladders in Burdwan Medical College, to analyse the association of Cholelithiasis with serum lipid profile, to compare the association of abnormal lipid profile of cholelithiasis patients with a control group and to study the histopathological changes in gallbladder in the study population, with special reference to cholesterosis and their association with serum lipid profile.

\section{METHODS}

The study was conducted after receiving approval from the ethical committee, Burdwan Medical College \& Hospital. For the study purpose patients admitted in the General Surgery ward were selected according to below mentioned inclusion and exclusion criteria. A proforma was used to record the history, clinical findings, investigations carried out for each case. Patient consent form mentioned the name of the study, name of the participant, age, sex, address and telephone number, annual registration number and Date. After taking informed consent, patient or her relatives (next of kin) will be asked a structured questionnaire. Participation in this study is not obligatory, but optional. If the patient wishes He/she may withdraw himself/herself from the study at any time. Participant's name, particulars \& data collected will be kept confidential \& will not be used for any purpose other than this study. Participants will not have to bear any expenses for participating in this study. This is a cross sectional study on the distribution of different types of gallstones in patients attending Burdwan Medical College \& Hospital with study area of Department of Pathology, Department of General Surgery \& Department of Biochemistry. Study period commenced from February-2014 and continuing till January2015. Study population included 54 calculous Cholecystitis patients who would undergo cholecystectomy for calculous cholecystitis in Department of General Surgery, Burdwan Medical College During the study period number of Cholecystectomy cases were recorded, and on the basis of that, sample size selected. 51 age and sex related control were selected. Age and gender matched non-cholecystectomy patients without hyperlipidaemia who were admitted and were willing to participate in the study were selected as control.. Not more than 51 could be obtained who fulfilled all those criteria. In the present study, all the calculous cholecystitis cases undergoing cholecystectomy were selected following the inclusion and exclusion criteria fixed for this study.

\section{Inclusion Criteria}

Sonologically diagnosed calculous cholecystitis cases among those who attended OPD, Burdwan Medical College \& Hospital.

\section{Exclusion Criteria}

Those with coronary heart disease, diabetes mellitus, HIV infection and carcinoma gall bladder were excluded from the study.

Patients with coronary heart disease and diabetes mellitus were excluded from the study because these patients have deranged serum lipid profile as either a cause or consequence of their primary diseases only. Hence any abnormality in serum lipid profiles in these patients could not be associated with cholecystitis directly, without elimination of these factors. Patients with HIV infection were excluded because sometimes they were not operated. Those with associated carcinoma of gall bladder were also not taken in the study population because they also have correlation with serum lipid profile which might have shown a spurious correlation with cholelithiasis. Study design: hospital-based cross-sectional study. Sampling design: All samples of surgically removed gallbladder masses fulfilling the abovementioned inclusion criteria were chosen randomly. Detailed clinical history will be taken from the patients. 
Parameters studied: detailed history taking pre-operative imaging study by ultrasonography, preoperative blood test for Glucose, HIV Serology and ECG. Serum lipid profile, gross appearance of the specimens, Histopathological examination after $\mathrm{H}$ \& $\mathrm{E}$ staining. Detailed history started with identification of the patient including name, age, religion, address, occupation followed by chief complaints. Following completion of history, complete general and systemic examinations were done. Routine investigations like total blood count, differential count of W.B.C., haemoglobin estimation, erythrocyte sedimentation rate, platelet count were done. USG of the whole abdomen was done as a routine first line investigation. Patients having sonological evidence of gall bladder stones were considered in the study population. Sample collection for biochemical examination: 2$3 \mathrm{ml}$ of venous blood was drawn in plain vials from the patients after overnight fasting and sent to the Department of Biochemistry, Burdwan Medical College. Measurement of serum lipid profile: By the use of the autoanalyser machine, following five parameters were measured-Total cholesterol, Triglycerides, High-density cholesterol, Low density cholesterol, Very low-density cholesterol. Sample collection for histopathological examination: Depending on the patients' age and anaesthetic fitness, either open cholecystectomy or laparoscopic cholecystectomy was done. All the specimens for histopathological examination were collected and sent to the Department of Pathology, Burdwan Medical College in formalin-filled containers.

\section{Statistical Analysis}

Data entry was done right after capture of relevant data for a given subject was complete. Statistical evaluation was done by appropriate statistical method using 'SPSS software for WINDOWS'. The mean value of the serum total cholesterol, triglyceride, HDL, LDL and VLDL of cholelithiasis patients were compared with those of the control groups using student's t-test for statistical analysis.

\section{RESULTS}

Among 105 patients, 54 patients (51.92\%) had cholelithiasis and 51 patients (48.57\%) who were admitted with some illnesses other than gallstones were selected as controls after application of exclusion criteria. Among 54 cases, maximum patients (29.6\%) were between 31 to 40 years of age [Fig. 1]. Only one patient was above 70 years of age. Mean age was 41.72 years. In our study, only 1 patient had pigment stone and the rest (i.e. 53 patients) had cholesterol stones [Fig. 3]. In the present series there were $75.9 \%$ females and $24.1 \%$ males. The male: female ratio was around 1:3. [Fig. 2]

Mean serum total cholesterol in the control subjects was $187.06 \mathrm{mg} / \mathrm{dl}$ with a SD of 40.97. Mean serum total cholesterol in the cholelithiasis patients overall was 216.43 $\mathrm{mg} / \mathrm{dl}$ with a SD of 51.31. The result showed that there was a significant increase in the serum total cholesterol [ $p$ value $0.002(<0.05)]$ in the patients with cholelithiasis in comparison to the control group.

As per the NCEP guidelines, $200 \mathrm{mg} / \mathrm{dl}$ was taken as the cut-off value of serum levels of total cholesterol. 15 out of the
51 controls (i.e., $29.4 \%$ of the controls) had serum total cholesterol level more than $200 \mathrm{mg} / \mathrm{dl}$. Whereas, 32 out of the 54 cases (i.e., $59.3 \%$ of the cases) had serum total cholesterol level more than $200 \mathrm{mg} / \mathrm{dl}$ [Table 1]. By chisquare test, there was significant association between high serum total cholesterol levels and cholelithiasis. [p value $<0.05]$

The mean value of the serum total cholesterol, triglyceride, HDL, LDL and VLDL of cholelithiasis patients were compared with those of the control groups using student's t-test for statistical analysis. The results showed that there was an overall increase in the serum total cholesterol ( $p$ value 0.002 ) and serum LDL ( $p$ value 0.001 ), but no significant change in the serum triglycerides (0.617), HDL (0.663) and VLDL (0.564) levels in cholelithiasis patients compared to the control group.

Comparison of the mean serum levels of total Cholesterol, TG, HDL, LDL AND VLDL of the cases with cholesterosis and those without were made. The results showed that there was no significant difference in any of the parameters in those cases showing cholesterosis compared to those not showing cholesterosis.
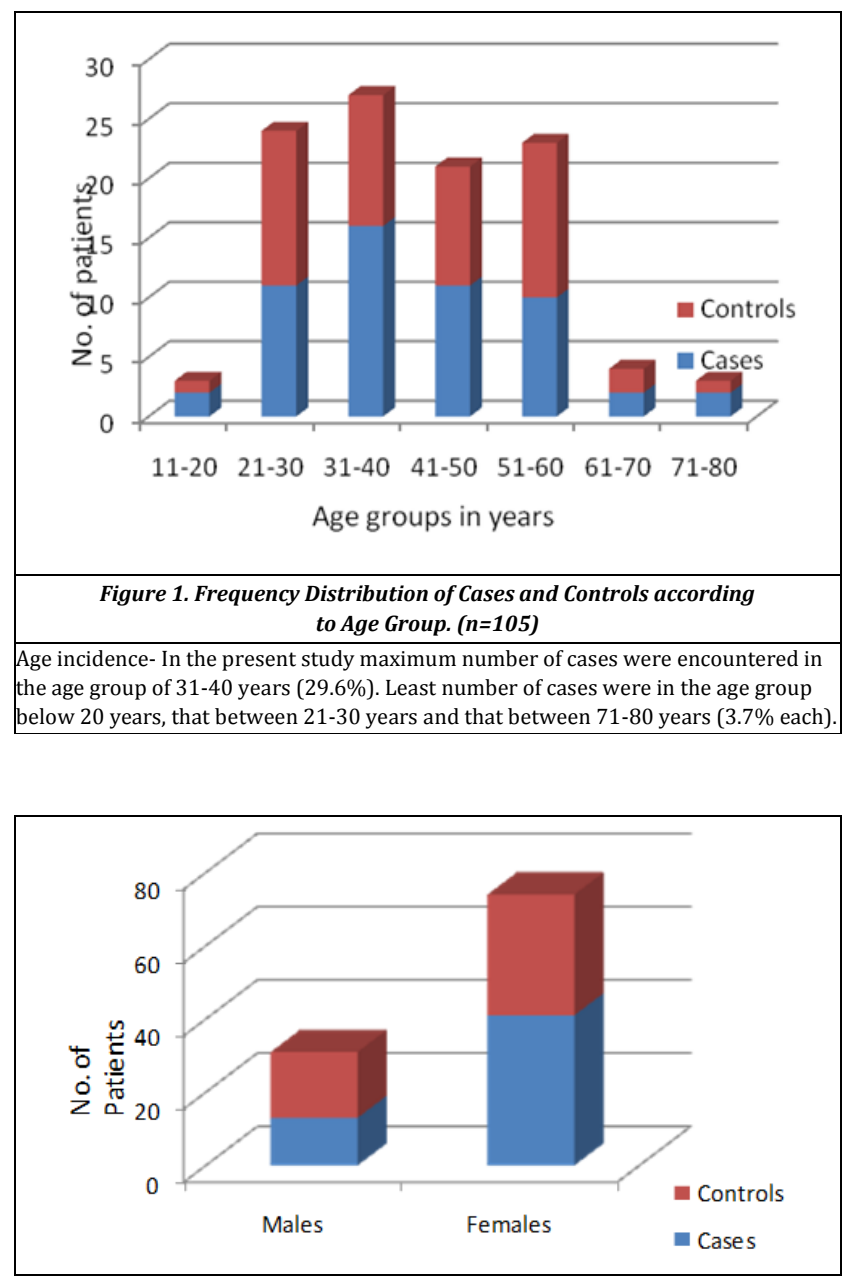

Figure 2. Frequency Distribution of Cases and Controls According to Sex (n=105) In the present series there were $75.9 \%$ females and $24.1 \%$ males. The male: female ratio was around 1:3 


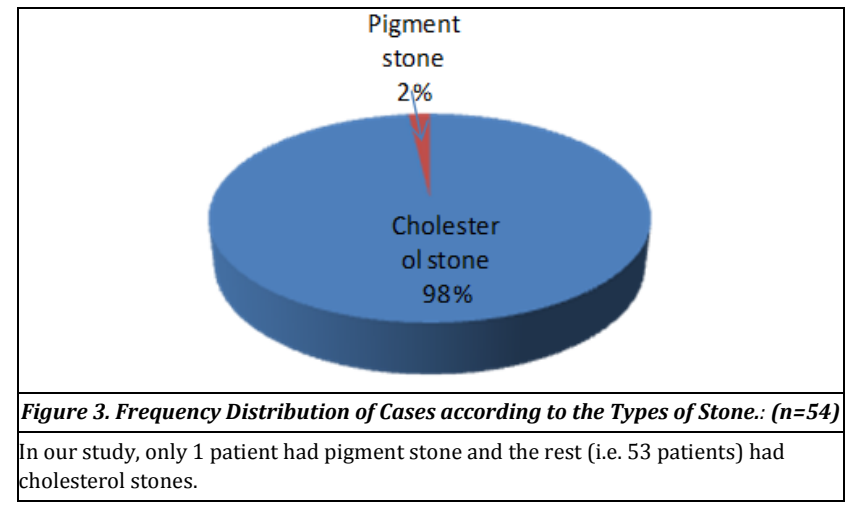

The mean value of the serum total cholesterol, triglyceride, HDL, LDL and VLDL of cholelithiasis patients were compared with those of the control groups using student's t-test for statistical analysis. The results showed that there was an overall increase in the serum total cholesterol ( $p$ value 0.002 ) and serum LDL ( $p$ value 0.001 ), but no significant change in the serum triglycerides (0.617), HDL (0.663) and VLDL (0.564) levels in cholelithiasis patients compared to the control group.

\begin{tabular}{|c|c|c|c|c|}
\hline Parameter & $\begin{array}{c}\text { With } \\
\text { Cholesterol } \\
\text { Stones } \\
\text { (Mean+-SD) }\end{array}$ & $\begin{array}{c}\text { With } \\
\text { Pigment } \\
\text { Stone }\end{array}$ & $\begin{array}{c}\text { Control } \\
\text { (Mean+-SD) }\end{array}$ & p Value \\
\hline $\begin{array}{c}\text { Serum total } \\
\text { cholesterol(mg/dl) }\end{array}$ & $218.45+-50.10$ & 139 & $187.06+-40.97$ & 0.002 \\
\hline $\begin{array}{c}\text { Serum } \\
\text { triglyceride(mg/dl) }\end{array}$ & $174.72+-52.35$ & 141 & $168.51+-61.73$ & 0.617 \\
\hline Serum HDL(mg/dl) & $46.08+-5.48$ & 45 & $47.22+-18.72$ & 0.663 \\
\hline Serum LDL(mg/dl) & $135.43 \pm 49.28$ & 74 & $104.65+-42.85$ & 0.001 \\
\hline Serum VLDL(mg/dl) & $34.91+10.44-$ & 28 & $33.49+-12.37$ & 0.564 \\
\hline
\end{tabular}

Table 1. Serum Lipid Profile of Cases with Cholesterol Stone ( $n=53)$ : and Pigment Stone ( $n=1)$ Comparison of the Parameters with Controls

The results showed that there was no significant difference in any of the parameters in those cases showing cholesterosis compared to those not showing cholesterosis.

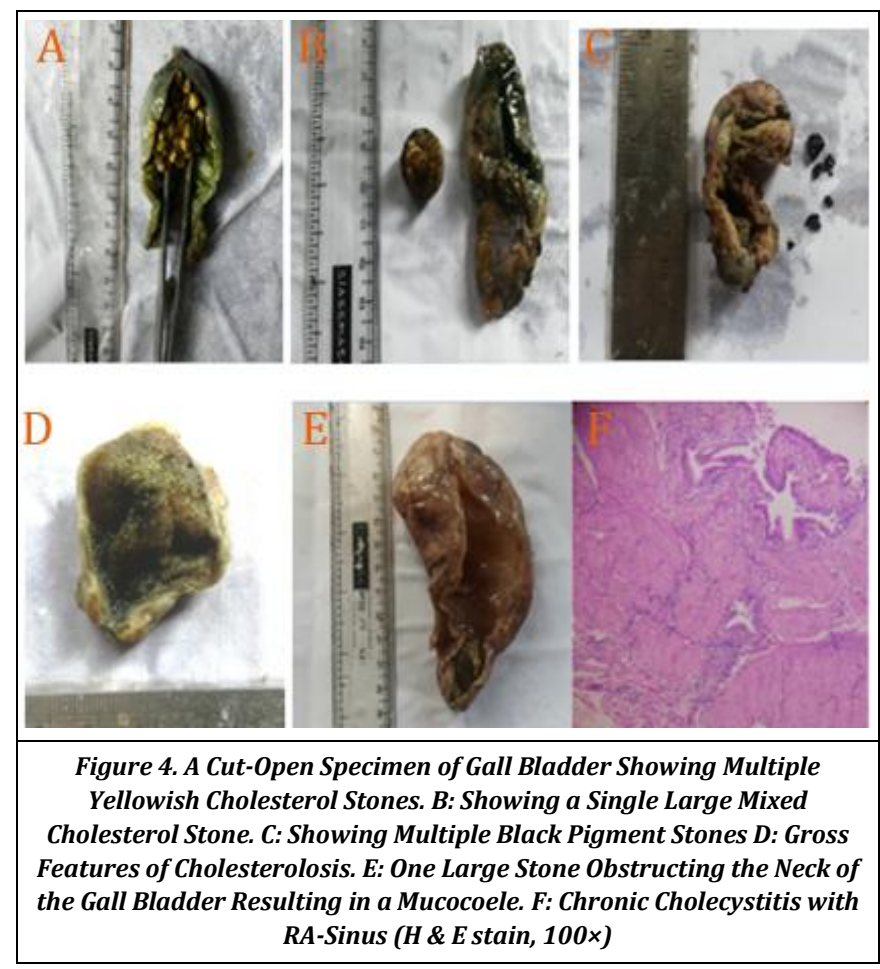

\section{DISCUSSION}

Gallstone disease is one of the most common gastrointestinal disorders, prevalent in about $10-15 \%$ of adults in the developed countries. The role of serum lipids in the aetiology of cholelithiasis is very important and in cholesterol gallstones serum lipids are altered which is suggestive of metabolic syndrome. Mean age group in the present study was 41.72 years as opposed to 60.2 years in the Brazilian series [1], and 45.88 years in the study by Nagaraj et al.[2]

The majority of patients in the present study was in the age group of 31-40 years, whereas in the Brazilian series was $>60$ years old ${ }^{[1]}$ and $41-50$ years in the study by Nagaraj et al.[2] Series by Herman et al showed peak incidence in 41-50 years age group. ${ }^{[3]}$ In western studies the peak incidence is in the 5 th and 6 th decades. The rise in the peak age of incidence is due to change in the dietary factor. Similar findings are noted in the studies of Ganey et al[4] and Moreaux et al.[5] Cholelithiasis was uncommon in the first two decades of life, with only 2 cases in our study being below 20 years. In the series of Ghosh SK et al and Shenoy et al series the highest incidence was found in the age group of 41-50 years. [6,7] Tyagi et al [8] showed highest incidence in 31-40 years while Bhansali et al showed highest incidence in 51-60 years. ${ }^{[9]}$

In the present series there were $75.9 \%$ females and $24.1 \%$ males. The male: female ratio was around 1:3. Sex distribution in the study by Nagaraj et al[2] showed a female to male ratio 2.57:1 while in Bockus et al study ${ }^{[10]}$ was 2.84:1. In Ghosh SK et al series,[6] the ratio was 1.5:9, in Goswami series $^{[11]}$ it was 1:2.5 and in Sharma LB series [12] it was 1:1.7. Malhotra series ${ }^{[13]}$ showed sex distribution of 1:1.5.

Framingham study[14] concluded that the overall incidence of gallbladder disease was about twice as high in women as in men, and it increased with age in both sexes without any evidence of an excess in the forties.

In the present study 53 patients (98.15\%) had cholesterol stones (including both pure and mixed types) whereas only 1 patient $(1.85 \%)$ had pigment stones. Other studies too showed a higher percentage of cholesterol stones and a much lower percentage of pigment stones. Only the study by Rakesh B et al [15] showed a higher percentage of pigment stones than cholesterol ones.

In the present study there was a statistically significant increase in the serum total cholesterol and serum LDL levels, but no significant change in the serum triglycerides, HDL and VLDL levels in cholelithiasis patients compared to the control group. This was in contrast with the observations of the study by Peela Jagannadha Rao[16] where the triglycerides in serum were not altered in the cholelithiasis patients, but the serum high density lipoprotein (HDL) and low-density lipoprotein (LDL) were increased $(\mathrm{p}<0.01)$ when compared with controls.

In the population-based study in China by Gabriella Andreotti et al,[17] compared to controls $(n=858)$, biliary stone cases $(n=981)$ had significantly lower mean levels of total cholesterol, HDL and LDL, but a significantly higher mean level of triglycerides.

The study by María Ximena Duque-L et al[18] showed strong inverse association between gallstone disease and 
plasma cholesterol concentration after adjusting for the risk factors like gender, age, and body mass index. A study by Singh Vinita et al[19] showed Serum LDLc, TC and TG levels in patients with gallstones significantly elevated $(\mathrm{P}<0.00 \mathrm{l})$ when compared to control. The Study by Narjis Hadi Al-Saadi et al[20] showed significant increases in the mean levels of serum total cholesterol, triglycerides and VLDL in cholelithiasis patients as compared to the controls whereas that by Batajoo et al[21] demonstrated significant increase in the mean serum level of LDL only. In contrast, our present study showed a significant increase in the mean levels of both total cholesterol and LDL cholesterol.

In the studies by Nagaraj et al[2] and Aulakh R. et al[22] respectively, the following mean values of serum lipid profile were found in cholelithiasis patients. There were variations in the mean serum lipid levels in cholelithiasis patients in different studies, which may be explained by the demography, age distribution and dietary habits.

\begin{tabular}{|c|c|c|c|}
\hline $\begin{array}{c}\text { Study } \\
\text { Variables }\end{array}$ & $\begin{array}{c}\text { Present } \\
\text { Study }\end{array}$ & $\begin{array}{c}\text { Study by } \\
\text { Nagaraj et al }^{[2]}\end{array}$ & $\begin{array}{c}\text { Study by Aulakh R } \\
\text { et al[22] }\end{array}$ \\
\hline $\begin{array}{c}\text { Serum Total } \\
\text { Cholesterol(mg/dl) }\end{array}$ & $218.45+50.10$ & $176.37 \pm 49.73$ & $155.50 \pm 43.03$ \\
\hline $\begin{array}{c}\text { Serum } \\
\text { Triglycerides(mg/dl) }\end{array}$ & $174.09 \pm 52.06$ & $192.60 \pm 85.01$ & $100.49 \pm 45.23$ \\
\hline Serum HDL(mg/dl) & $46.06 \pm 5.43$ & $33.58 \pm 06.50$ & $46.71 \pm 15.20$ \\
\hline Serum LDL(mg/dl) & $135.43 \pm 49.28$ & $110.81 \pm 34.72$ & $87.94 \pm 36.85$ \\
\hline Serum VLDL(mg/dl) & $34.78 \pm 10.38$ & $38.57 \pm 16.97$ & $20.84 \pm 11.97$ \\
\hline \multicolumn{4}{|c|}{ Table 2. Comparison of Mean Serum Lipid Levels of } \\
Cholelithiasis Patients in Different Studies \\
\hline
\end{tabular}

In the Framingham study no relationship was demonstrated between serum cholesterol level and gallbladder disease. ${ }^{[14]}$ In another study by T. Jorgensen, in the univariate analysis gallstone disease was significantly associated with high triglyceride and low high-densitylipoprotein cholesterol.[23] No significant association among gallstones and total cholesterol and low-density-lipoprotein cholesterol was seen. In multivariate analyses triglyceride lost its significant association with gallstone disease, whereas total cholesterol became negatively associated with gallstones. [23] The study by Khairy GA et al [24] showed a slightly higher incidence of cholesterosis than our present study.

\section{CONCLUSIONS}

Gallstone disease is common in the age group of 31-40 years. There is a female preponderance. Cholesterol stones constitute the majority among the main two types of stones. There was a statistically significant increase in the serum total cholesterol and serum LDL levels, but no significant change in the serum triglycerides, HDL and VLDL levels in cholelithiasis patients compared to the control group. There was a significant association of cholelithiasis with high serum cholesterol ( $>200 \mathrm{mg} / \mathrm{dl})$ and LDL ( $>130 \mathrm{mg} / \mathrm{dl})$ levels and, but no such association was found with high serum triglycerides $(\geq 150 \mathrm{mg} / \mathrm{dl}$ ) or low serum HDL $(<40 \mathrm{mg} / \mathrm{dl})$ levels. There was no significant change in serum lipid profile of the patients with cholesterosis compared to those without.

But many other risk factors, like weight, body-mass index, waist-hip ratio, socio-economic status and dietary habit were not taken into consideration in this study, which might have contributed to the differences in observation from some other related studies as mentioned. However, it can be concluded that gallstones should not only be regarded as the condition requiring cholecystectomy, but also as a marker of an underlying metabolic disorder that has to be investigated and treated accordingly. All patients who have cholelithiasis should now have a full serum lipid profile as a routine part of their clinical assessment. Considering the major role of LDL in coronary artery disease, it would be prudent to screen all patients with cholelithiasis for dyslipidaemia. This might help in instituting primary preventive measures.

\section{REFERENCES}

[1] Coelho JC, Bonilha R, Pitaki SA, et al. Prevalence of gallstones in a Brazilian population. Int Surg 1999;84(1):25-8.

[2] Nagaraj SK., Paul P, Kumar MK., et al. Risk factors and the biochemical evaluation of biliary calculi in rural Kolar, Karnataka, India: a rural perspective of an urban disease. Journal of Clinical and Diagnostic Research 2012;(Suppl1):6(3):364-8.

[3] Hermann RE. Biliary disease in the aging patients. New York: Masson 1983: p. 227-32.

[4] Ganey JB, Johnson PA Jr, Prillaman PE, et al. Cholecystectomy: clinical experience with a large series. Am J Surg 1986;151(3):352-7.

[5] Moreaux J. Prospective study of open cholecystectomy for calculous biliary disease. Br J Surg 1994;81(1):116-9.

[6] Ghosh SK, Das KN, Bose D, et al. Aetiopathogenesis of chronic cholecystitis in Gangetic West Bengal - a study of 300 cases. Ind J Surg 1995;57:313-6.

[7] Shenoy UAK, Nayak MN, Shenoy MG, et al. Cholelithiasis in Manipal. Ind J Med Res 1982;76:454-7.

[8] Tyagi SP, Tyagi N, Maheswari V, et al. Morphological changes in diseased gall bladder: a study of 415 cholecyscectomies at Aligarh. J Ind Med A 1992;90(7):178-81.

[9] Bhansali SK. Cholelithiasis and cholecystitis (an appraisal of clinico-surgical experiences with 228 cases). J Postgrad Med 1980;26(1):74-85.

[10] Bockus HL, Chapman MJ, Worobetz LJ, et al. Symptomatic gallstone disease in Spanish population. J Gastroenterol 2004;39(6):576-84.

[11] Goswami M. An analysis of 160 cholecystectomies at Guwahati. Ind J Surg 1999;61(4):252-5.

[12] Sharma LB, Agarwal $M$, Rastogi AN, et al. Cholecystectomy under local anaesthesia. Ind J Surg 1999;61(1):33-5.

[13] Malhotra SL. Epidemiological study of cholelithiasis among railroad workers in India with special reference to causation. From the Medical Department, Western Railway, Bombay, India. Gut 1968;9(3):290-5.

[14] Friedman GD, Kannel WB, Dawber TR. The epidemiology of gallbladder diseases. Observations in the Framingham study. J Chronic Dis 1966;19(3):273-92.

[15] Rakesh BH, Rajendra GC. A prospective clinicopathological study of 50 cases of chronic calculous cholecystitis in the local population. Journal of Evolution of Medical and Dental Sciences 2013;2(35):6706-16. 
[16] Jagannadharao P, Jarari A, El-Awami H, et al. Lipid profile in bile and serum of cholelithiasis patients - a comparative study. Journal of Basic Medical and Allied Sciences 2012;1(2).

[17] Andreotti G, Chen J, Gao YT, et al. Serum lipid levels and the risk of biliary tract cancers and biliary stones: a population-based study in China. Int J Cancer 2008;122(10):2322-9.

[18] Duque MX, Morán S, Salmerón-Castro J, et al. Inverse association between plasma cholesterol and gallstone disease. Archives of Medical Research 1999;30(3):190-7.

[19] Singh V, Zaidi SA, Singh VS. Lipids in biliary lithogenesis. Journal of Pakistan Medical Association 1997;47 (10):253-5.

[20] Al-Saadi NH, Al-Ardhi SA. Biochemical and demographical study of lipid profile in sera of patients with gallstone. Iraqi Journal of Science 2012;53(2):7608.

[21] Batajoo H, Hazra NK. Analysis of serum lipid profile in cholelithiasis patients. J Nepal Health Res Counc 2013;11(23):53-5.

[22] Aulakh R, Mohan H, Attri AK, et al. A comparative study of serum lipid profile and gallstone disease. Indian J Pathol Microbiol 2007;50(2):308-12.

[23] Jørgensen T. Gallstones and plasma lipids in a Danish population. Scandinavian Journal of Gastroenterology 1989;24(8):916-22.

[24] Khairy GA, Guraya SY, Murshid KR. Cholesterolosis. Incidence, correlation with serum cholesterol level and the role of laparoscopic cholecystectomy. Saudi Medical Journal 2004;25(9):1226-8 